\title{
Después del auge. Campos de poder en el valle del Monzón ${ }^{+}$
}

\author{
CHRISTOPH HEUSER* \\ German Institute of Global and Area Studies in Hamburg (GIGA) \\ christoph.heuser@giga-hamburg.de \\ https://doi.org/10.18800/rcpg.201701.005
}

\section{RESUMEN}

Este artículo trata de explicar la influencia que tiene una economía ilegal en las estructuras de poder en una región al margen del Estado. Aún no tenemos un entendimiento claro sobre la influencia de economías ilegales en el orden local. En ese sentido, el concepto de campos de poder de Pierre Bourdieu ofrece herramientas analíticas que permiten dilucidar de una forma más precisa la relación entre poder y economía ilícita. El caso de estudio en el valle del Monzón ofrece de esta manera una oportunidad para investigar el efecto que genera la economía de la coca como factor predominante durante el periodo del boom. Asimismo, podemos analizar el efecto de la economía ilícita tras ser destruida por el Estado. Este panorama nos brinda un mejor entendimiento sobre las economías ilícitas y la intervención del Estado.

Palabras clave: Poder, intervención del Estado, políticas de droga, Perú.

\section{After the boom. Fields of power in the Monzón valley}

\section{Abstract}

This article tries to explain what influence an illicit economy has on power structures in the margins of the state. Still, academic understanding on the influence of illegal economies on local order is limited. The concept of fields of power by Pierre Bourdieu offers analytical tools which allows to track more precisely the relationship between illicit economies and power. The case study on the valley of Monzón allows to present the effect of the coca economy as predominant factor during a boom period. The destruction of the coca economy by the Peruvian state offers on the other hand the opportunity to analyze the loss of this determinant factor for the power structures in a society. The article shows the importance for an illicit economy for the local field of power. This gives a better understanding on the influence of illicit economies and the effect of state intervention.

Key words: Power, State Intervention, Drug Policy, Peru.

\footnotetext{
* Investigador y estudiante de doctorado del German Institute of Global and Area Studies (GIGA) en Hamburgo. Además es docente de Ciencias Políticas y ha trabajado como experto en el sector de desarrollo internacional.

+ Recibido el 15 de febrero de 2017; aceptado el 17 de mayo de 2017.
} 



\section{INTRODUCCIÓN}

La mayoría de análisis sobre el efecto de las economías ilícitas en las estructuras del Estado son planteados desde una perspectiva macro, concluyendo que las actividades ilegales tienden a debilitar al Estado. Sin embargo, su comprensión sobre el Estado se deriva de una visión europea sobre la formación del mismo, pasando por alto que la mayoría de Estados se desarrollaron de maneras distintas. En la mayoría de Estados, por ejemplo, existen regiones dentro de sus fronteras pero que poseen reglas diferentes, que quedan fuera del control estatal. O’Donnell $(1993,2004)$ las llamó «zonas marrones» (brown areas). Son regiones subnacionales donde se puede encontrar una regla alternativa a la del Estado y que coexiste con el régimen democrático. Esto es válido para la mayoría de los Estados latinoamericanos sin un control cohesivo sobre todo el territorio (Kurtz, 2013; Soifer, 2015). Muchas de estas áreas se caracterizan por lo que podríamos llamar «economías ilícitas». Aunque todavía no entendemos bien la relación entre estas economías ilícitas y el Estado, ya que los trabajos académicos se enfocan muchas veces en actores o grupos directamente vinculados con esta economía y cómo ellos usan ese poder de forma directa (Abello-Colak y Guarneros-Meza, 2014; Arias, 2006). Otros trabajos nos cuentan que la relación con una economía ilícita de facto ayuda a fortalecer el control territorial del Estado (Meehan, 2015) o la formación de formas de control (Andreas, 2013; Meagher, 2014). Pero pocos trabajos se concentran en el rol de las economías ilícitas de los poderes en una sociedad sin alta influencia del Estado (Arias, 2010).

Este artículo plantea que la economía ilícita en regiones marginales del Estado es menos un peligro para el Estado en sí que una cuestión de orden social, lo que es definido por relaciones de poder (Lukes, 1978; Bourdieu, 1990; Haugaard, 1997). Por eso, el concepto de campos de poder de Bourdieu (1994, 1984) amplía el análisis. Más allá de un enfoque en los actores directamente vinculados con una economía ilícita, lo que ofrece el concepto de campo de poder es una herramienta para estudiar el juego de los poderes en detalle. El argumento principal de este artículo es que una economía ilícita no solo empodera actores al margen del Estado, sino que produce un sistema en donde la relación entre distintos actores poderosos está vinculado por la economía ilícita. Entender esta relación es importante para comprender mejor la influencia de las economías ilícitas en una sociedad al margen del control estatal. Además, nos permite analizar mejor los cambios en una sociedad aislada cuando el Estado decide actuar en ellas. 
En un caso de estudio del valle del Monzón, en Perú, se analiza el efecto de transformación de una economía ilícita en los campos de poder. En esta zona el cultivo de coca y la economía de drogas ilícitas han sido el primer factor de atracción para la migración y la base económica para la población (van Dun, 2009). Esto fue impulsado por la demanda externa de drogas ilícitas, pero tuvo consecuencias locales ${ }^{1}$. Este artículo se encuentra dentro del panorama de trabajos recientes sobre zonas cocaleras, economías ilícitas y el Estado en el Perú (Zevallos, 2016; López y Tuesta, 2015), así como trabajos sobre enfoques conceptuales en esta área de estudios (Vizcarra y Zevallos, 2015).

Se analizarán dos puntos principales. Primero se presenta que las economías ilícitas no solo influyen en la economía, sino también influyen y constituyen el poder local en ausencia del Estado. En segundo lugar, se muestra que un cambio de la economía ilícita por las acciones del Estado tiene consecuencias severas no solo económicas, sino también radicales en los poderes de la sociedad. Se analizará el campo de poder de la coca en relación con el Estado para estudiar la naturaleza compleja de una sociedad de la coca dentro de un régimen de prohibición. Por lo tanto, se usa los conceptos del capital económico, político y social de Bourdieu, y se introduce el capital coactivo como forma de acumular influencia ${ }^{2}$. El estudio presenta un modelo para analizar cómo la acumulación de poder está vinculada a la economía ilícita, que cambia cuando esta economía es destruida.

\section{BOURDIEU, EL CAMPO Y LA COCA}

Según Bourdieu (1984), un campo es una red de relaciones que interactúan de manera autónoma con otros campos. Tiene sus propios «nomos», que pueden ser entendidos como una forma de constitución, que lo hace distinguible de otros campos (Müller, 2014, p. 78). Si bien Bourdieu tenía en mente una sociedad Europea cuando desarrolló y aplicó sus conceptos, estos siguen siendo útiles para nuestro propósito de analizar los campos de la producción de coca. Nos permite representar la posición y las relaciones de poder entre los diferentes actores de una sociedad dada. Además nos ayuda a presentar el efecto concreto de una economía ilícita en un orden social y en personas poderosas.

\footnotetext{
1 Se presentan resultados de una investigación de campo realizada en octubre y noviembre de 2015 y febrero de 2016. Durante este estudio se realizaron entrevistas semiestructuradas, encuestas con la población y las autoridades locales, y se hizo observación participante.

2 Con este concepto se trata también de explicar por qué el periodo de posterradicación y promoción del control (Devida, 2015) es un proyecto complicado y largo.
} 
Entender esto nos permitirá diseñar mejores sistemas para confrontar y generar posibles cambios en espacios con una economía ilícita.

De esta manera, con el concepto de campos de poder podemos distinguir a través del poder de ciertos actores que dependen del «capital» dentro de un campo y la regla de un campo. Para Bourdieu (1986), el poder se basa en la desigualdad y en la distribución del «capital» social, político y económico, que define las posiciones en un campo. En el caso especial de Monzón, se ofrece el «capital coactivo» como nueva forma de capital.

- Social: principalmente redes, relaciones sociales, contactos.

- Económico: capital monetario o capital de intercambio fácil; en un mundo capitalista, es probable que sea más fácil de cambiar por otro capital.

- Político: como una forma de capital que es un subproducto del capital social, ganado por la confianza de los demás dentro del campo de poder. Bourdieu distingue dos tipos: personal y delegado. El primero está vinculado a una persona y se presenta típicamente por popularidad o carisma ${ }^{3}$. El segundo tipo es el capital delegado a una organización o una institución (Bourdieu, 1991).

- Para comprender el campo donde no hay un monopolio de violencia se incluye una nueva forma de capital: capital coactivo. El capital coactivo describe la posibilidad de utilizar y movilizar medios coactivos. En las regiones sin un monopolio de la violencia, la posesión de medidas coactivas resulta una ventaja comparativa para otros actores dentro del mismo campo. Esto a su vez resulta en una posición más alta dentro del campo de poder.

La estrategia para la acumulación de capital y el intercambio de diversos tipos de capital para mejorar la posición en el mundo social, son centrales para la comprensión. El capital es intercambiable, pero en un juego de suma cero (Swartz, 2013, pp. 53-55). Así, uno está ganando más capital en oposición a otro. Por ejemplo: el uso de medios coactivos puede conducir a un mayor capital social, ya que la gente necesita actores que tengan la capacidad de proteger sus bienes para tener más influencia en decisiones políticas. Este «juego» o lucha se muestra dentro del «campo». La posición dentro del campo depende del capital acumulado y de la relación con otros sujetos en el campo. En ese sentido, podemos entender a la sociedad como un mercado en donde se define

3 Lo último está cerca de la definición de Max Weber de «carisma» (Weber, 2010). 
su posición dependiendo de su capital acumulado. Esto da lugar a un arreglo relacional dentro del campo, y el concepto de Bourdieu nos permite desplegar un cuadro de posiciones y posiciones tomadas, que están conectadas entre sí y que mantienen relaciones dinámicas (Bourdieu, 1993, p. 30). Además, podemos especificar cómo los capitales están cambiando debido a la transición de la economía ilícita a una economía lícita controlada por el Estado.

Es posible captar el papel que juegan diferentes actores e instituciones dentro de un territorio de cultivo de coca, así como las relaciones con «el Estado». El análisis de campo de Bourdieu dará una visión general de la constelación de actores y la relación de los diferentes campos entre sí. Así, el concepto abre posibilidades analíticas para capturar los procesos locales en relación con el Estado. También captura procesos y estructuras sociales, incluyendo economías ilícitas que pueden convertirse en un aspecto definitorio en áreas con bajo control del Estado.

\section{Después del auge. El valle del Monzón}

Es temprano en la mañana. Una comerciante abre su pequeña tienda, tirando de la persiana que ajusta el mostrador donde espera vender parte de su mercancía, desde papas hasta sandalias. No enciende las luces, «la electricidad es demasiada cara», dice ${ }^{4}$. Luego se sienta en su mecedora de plástico frente a la tienda y espera a los clientes. Es un comienzo típico del día, dice ella mirando a la carretera principal delante de su tienda. Una carretera de "grava» llena de agujeros. Solo un pequeño grupo de hombres de mediana edad en overoles y cascos camina por la calle, en dirección a la nueva construcción de la planta hidroeléctrica. Aparte de estos trabajadores de la construcción, hay pocos signos de actividad laboral. Aunque abrió su tienda como todos los días, la comericante no está esperando a nadie:

-Ya no hay gente y no hay dinero, la gente no tiene dinero. La economía es mala.

- ¿Por qué es así?

-Porque ya no hay coca.

Pocas personas se pueden ver en el rango de 18 a 35 años que no estén trabajando para la construcción de la planta hidroeléctrica5.

\footnotetext{
4 Se ha optado por mantener el anonimato de los entrevistados, estos son presentados en este estudio como pobladores o de acuerdo a su rol en la sociedad.

5 Con los resultados del nuevo censo que va a ser publicado después de la redacción de este estudio se podrá analizar los efectos demográficos de la erradicación más en detalle.
} 
El centro del distrito de Monzón, que en otro tiempo se veía abrumado, es ahora un lugar demasiado tranquilo, por ello es difícil imaginar que fue el epicentro de producción y tráfico de drogas en Perú.

Para llegar al valle del Monzón se necesita alrededor de dos horas en coche desde el centro regional de Tingo María, esto nos muestra que Monzón aún se encuentra al margen de un centro económico. Anteriormente, la población vivía principalmente del cultivo de la hoja coca paralela a la producción de pasta básica de cocaína (PBC), mientras que los servicios básicos por parte del Estado estaban ausentes. Las dinámicas son similares a las del resto de la región del valle del Alto de Huallaga. Hasta 2012, Monzón era esencialmente la última gran área de producción de coca y PBC, mientras que en el resto del Alto Huallaga la coca ya se encontraba erradicada. Resguardado por colinas escarpadas, y solo accesible por una carretera, el valle era como una fortaleza natural, cerrada para la mayoría de la gente fuera de Monzón. El distrito de Monzón forma parte del departamento de Huánuco, en la selva central, y constituye en muchos aspectos un distrito subdesarrollado en el Perú. El acceso por carretera es difícil, así como el acceso a electricidad o suministros de agua. El nivel de pobreza antes de la erradicación era de 62,8\%, mientras que la pobreza extrema representó el 17,4\% (39,3\% y 13,7\% respectivamente a nivel nacional) (INEI, 2007). Aún más llamativa es la tasa de hogares sin servicios de información y comunicación, que era de 95\%, mientras en el resto del país el nivel fue de 47\% (INEI, 2007). Un trabajador social que entró en el área en 2009 dijo: «no había acceso a la red de [telefonía] móvil, nada [...]. La gente estaba completamente aislada». Solo el $10 \%$ tenía acceso a la electricidad y el $22 \%$ a un sistema de alcantarillado y drenaje. Aún hoy, solo el $8,5 \%$ de los hogares de Huánuco tiene acceso a Internet, mucho menos que el 23,5\% a nivel nacional (INEI, 2014). Durante tres décadas, la economía de la coca fue el ingreso económico más importante de la zona, y generando un gran impacto en el gobierno local.

Tres periodos son particularmente importantes para comprender el campo de poder de Monzón. 1) El periodo de la década de 1960, que incluye una ola migratoria, hasta inicios de la década de 1980, cuando Sendero Luminoso empezó a ganar cada vez más poder e influyó en el orden local en el valle del Alto Huallaga. Como en otras partes de la región, la guerrilla de Sendero Luminoso fue primero acogida como un escudo contra la amenaza de la erradicación. Pero esto cambió y en la memoria de la población local el dominio de la guerrilla sobre la población fue brutal; y cuando Sendero Luminoso abandonó el valle, fue considerado una salvación (van Dun, 2009). No es del todo 
seguro cuándo se marchó la guerrilla, ya que hay reportes recurrentes de remanentes de la guerrilla incluso hasta hoy en día durante entrevistas en la zona. Pero muchos habitantes indicaron que fue a finales de la década de 1990 el momento en que sendero luminoso se dispersó y abandonó la zona. Otro de los factores que influyó en el cambio de contexto en el Monzón fue que las medidas restrictivas del régimen de Fujimori ayudaron en este sentido, ya que lucharon contra el narcotráfico. 2) El segundo periodo se da entre mediados y finales de la década de 1990, la producción de coca entró en crisis y solo se recuperó durante este segundo periodo, que fue moldeado por la regla de los cocaleros. El líder cocalero apoyó la economía ilícita y pudo unir al pueblo de Monzón contra una amenaza común: la erradicación de la coca por parte del Estado. Durante este periodo básicamente ningún agente estatal ni ningún extraño tuvo gran influencia, ni pudo entrar al valle sin permiso de los líderes cocaleros. Este periodo continuó hasta que 3) la campaña de erradicación por parte del Estado comenzó en 2012, que marca el inicio del último periodo hasta el momento: Monzón bajo control estatal.

Para el segundo periodo se puede argumentar que los campos de poder fueron impulsados por la economía ilícita. Este artículo se centra en este «campo de poder de la coca» y en el periodo postcoca que está definido por una transición a la regla estatal.

\section{EL BOOM DE LA COCA}

En 2003 Monzón representó el 78\% de la producción total de coca en el valle del Alto Huallaga. Solo un 1\% fue vendido a Enaco, la agencia nacional para la comercialización de la coca, el resto fue producido para el mercado negro (Durand Ochoa, 2014, p. 120; Redacción LR, 2004). Las razones económicas de la producción de coca son similares a las de otras regiones. Enaco paga precios dependiendo de la calidad de hoja de coca y de las ventas ilegales de coca, aproximadamente el doble del precio que Enaco está pagando por la mayoría de las hojas (UNODC, 2012). Además, hay posibilidades limitadas de alternativas, pues las colinas empinadas limitan el espacio de extensión de campos agrícolas. La economía ilícita se organizó como en la mayoría de las otras zonas del Alto Huallaga, pero en Monzón la producción ilegal de coca y drogas era más constante. Esto se puede reflejar en cifras, por ejemplo, cuando el Estado lanzó una operación en 2003 para destruir las instalaciones de producción de drogas, se destruyeron 76 laboratorios, se incautaron 1450 kilos de coca seca y 1199 toneladas de PBC (Caretas, 2003). 
La creación de campos de poder se basa en el desarrollo histórico local que influye en las normas y creencias compartidas de la población. Mientras que la región periférica creó sus propias reglas y normas, el Estado peruano siguió el régimen de prohibición internacional que amenazaba los medios de subsistencia de la población local. Esto creó un campo exclusivo y una racionalidad interna-externa, en el que la gente sentía que necesitaba defender sus medios de subsistencia contra desconocidos. De esta manera, la ilegalidad de la economía local generó que los habitantes de Monzón se muestren suspicaces hacia la gente foránea. Cuando se le preguntó por la regla más importante durante la época del segundo boom de la coca, un excocalero dijo: «Ah, las reglas importantes eran que tienes que ser conocido para ingresar al valle, si no eres conocido, alguien tiene que garantizar para que tu ingreses y el resto ya era cosa de que ellos imponían su justicia popular». La razón detrás de esta regla era sobre todo el miedo de que un desarrollo alternativo de la coca al final va de la mano con una erradicación de esta. Incluso hoy en día los extraños son observados y tratados con cautela. La primera vez que entré en el valle durante la investigación de campo, me preguntaron varias veces si trabajaba para una agencia antidroga, una situación que se repitió en varias otras ocasiones. Aunque hablé con las autoridades locales y expliqué a detalle lo que estaba haciendo, durante una entrevista una antigua autoridad local me dijo, después de que expliqué el propósito de mi visita:

-Yo te conozco. Sé que estás aquí caminando, hablando con la gente. La gente me dijo que eres un agente. Había otro agente aquí caminando, igual que tú. Lo echaron.

- No, yo no soy un agente.

—Trabajas para la DEA, ¿eh? ¿Para Interpol?

Actualmente, los extranjeros que se ven en Monzón suelen ser funcionarios públicos o trabajan en proyectos de infraestructura lanzados por el Estado, pero por costumbre la población aún los trata con sospecha. Antes de la erradicación en la región, el sistema de ingreso a la zona era restringido, por ello muy pocas personas podían entrar desde el exterior. Y los extranjeros que se encontraban en la zona estaban relacionados a la participación de una economía de la droga. El valle de Monzón era un campo autónomo y cerrado

\section{El CAMPO DE PODER DE LA COCA}

Durand Ochoa cita a un funcionario de Devida en el contexto del boom de la coca: «El Estado no existe allí. La única institución que ha podido entrar es la $\mathrm{PEAH}$, que inició las obras de agua y alcantarillado y esto solo tuvo lugar con el 
permiso de los líderes cocaleros» (Durand Ochoa, 2014, p. 120). Incluso agentes estatales, como el gobernador regional, estaban presentes, pero su influencia era muy baja, mientras que el alcalde, elegido por el pueblo de Monzón, desempeñó un papel esencial. Después que la influencia de Sendero Luminoso se perdiera en el valle, el alcalde fue visto como la autoridad más poderosa, el «líder del valle» (a decir de distintos pobladores entrevistados), que además era un líder cocalero y se convirtió en el principal representante del valle ante el Estado. La importancia de Monzón como un centro de producción para la coca extrajudicial alimentó la importancia del papel del alcalde, dándole capital político para la representación del valle. En este sentido, el alcalde dirigió las negociaciones y las huelgas. La figura más influyente fue Iburcio Morales, quien se hizo nacionalmente conocido como dirigente cocalero y alcalde de Monzón. Morales representó al valle al exterior e interior del campo de poder. Fue arrestado en 2010 por su supuesta cooperación con terroristas y cuando murió en la cárcel en 2012, el presidente de las autodefensas en Monzón dijo: «Estamos dolidos por la muerte de nuestro líder» (Correo, 2012). Los líderes cocaleros locales argumentaron que la coca era el único producto que podía proveer ingresos suficientes y que no había alternativa: «El resto no da» (Redacción LR, 2004); «Coca o muerte» se convirtió en una famosa expresión. La memoria del campo de poder y de los cocaleros es ambivalente. Por un lado, la gente considera que este periodo tornó a su zona en «tierra de nadie», una región violenta libre de reglas, y con muchas muertes ${ }^{6}$. Por otro lado, excocaleros, taxistas y comerciantes de la zona argumentan exactamente lo contrario, que durante la ley del cocalero el valle estaba unido en un ambiente tranquilo y sin robos.

Los líderes cocaleros tuvieron un papel excepcional durante la época del boom de la coca. Tras el análisis de campo, el poder principal de los cocaleros se basó en el capital social y el capital económico, en el sentido de Bourdieu. Los líderes cocaleros tenían una red social densa y se situaban en una posición alta dentro del campo de poder, y las decisiones que se tomaban para la comunidad necesitaban tener su apoyo. Los líderes actuaron como una autoridad política y fueron básicamente los actores más poderosos de la región. Como todos dependían de la coca y de sus posibilidades económicas, la mayor parte del poder político dependía de sus líderes. Eso incluía el orden de castigo; por ejemplo por incumplimiento, que implicaba la destrucción de los cultivos; pero también castigos corporales al que decidía no participar en una manifestación:

\footnotetext{
6 Sin embargo, no siempre está claro si la gente se refería a la norma de la guerrilla o a la norma de los cocaleros, puesto que la percepción del tiempo y la historia es borrosa y los periodos en la memoria de la gente no queda del todo claro.
} 
«Cuando querían que fueras a una manifestación, tenías que ir. Sino, destruían tu campo y amenazaban a ti y a tu familia». El capital económico de los líderes cocaleros también era muy significativo. En una región que era intransitable para desconocidos y financiada principalmente a través de la producción y la venta de bienes ilegales, es difícil dar cuenta de los ingresos exactos. Pero como los dirigentes cocaleros formaban la cúpula de todos los productores de coca, es probable que también obtuvieran la mayor parte de la ganancia. Durante el gobierno cocalero, la economía ilícita fue aceptada y promovida por las autoridades locales, formaba parte de la economía cotidiana y de la vida cotidiana. Finalmente, los cocaleros asumieron un capital político muy alto. Los líderes cocaleros, elegidos por los cocaleros, estaban en posición de influir en la población dentro del valle.

En la primera mitad de la década de 2000, los cocaleros tuvieron un movimiento nacional y llegaron a acuerdos con el Gobierno nacional durante la administración de Alejandro Toledo7. Los cocaleros de Monzón fueron uno de los grupos más agresivos en sus demandas hacia el Estado y rechazaron los acuerdos de una erradicación concertada. Sus demandas incluyeron un paro inmediato de la erradicación forzada y el libre comercio de la coca (Durand Guevara, 2005). Iburcio Morales apareció como el actor más importante en su función de líder cocalero. Asumió no solo el apoyo por coerción, sino también por la legitimidad que le otorgaba la gente por ser el líder de la resistencia en contra de una posible erradicación. Muchos recuerdan a Iburcio Morales como un buen ejemplo de líder, un poblador lo recuerda de esta manera: «Fue una persona que luchó por nuestro pueblo». A decir de los pobladores, su actitud hacia el Estado fue negativa, en el sentido que entendió las opciones entre «no presencia del Estado» y libre comercio de la coca o "presencia del Estado» y erradicación en el valle. Esta posición extrema fue apoyada por la mayoría de la población. Por tanto, la «amenaza» de una erradicación forzada de parte del Estado respaldó el capital político de los líderes cocaleros.

El narcotráfico atrajo también a otros grupos de actores importantes e influyentes para la economía ilícita. E incluso si su base de poder pudo haber diferido, sus actitudes hacia la coca y el Estado eran iguales (tabla 1). Todos apoyaban la economía de la coca y todos tenían una actitud negativa hacia el Estado. La influencia económica y política o social no puede ser completamente separada. Están muy entrelazadas, ya que la economía se basaba principalmente en un solo producto. Las personas que controlaban partes más grandes o importantes

Para un buen análisis de los movimientos cocaleros, véase Durand Ochoa (2014) y Durand Guevara (2005). 
de esta cadena económica tenían mayores niveles de influencia. Había un sistema de interrelaciones entre los líderes políticos y los narcotraficantes (Mella, 2012). Los líderes políticos apoyaron la economía ilícita, tal vez no activamente pero aseguraron que la producción diera un resultado económico para su pueblo. Por otro lado, los actores ilícitos dependían de su apoyo político para poder entrar en el valle del Monzón.

Tabla 1. Actores poderosos en Monzón antes de la erradicación

\begin{tabular}{|l|l|c|c|c|}
\hline \multirow{5}{*}{ Influencia } & \multicolumn{1}{|c|}{ Actor } & $\begin{array}{c}\text { Base de poder } \\
\text { (capital) }\end{array}$ & $\begin{array}{c}\text { Actitud hacia } \\
\text { la coca }\end{array}$ & $\begin{array}{c}\text { Actitud hacia } \\
\text { el Estado }\end{array}$ \\
\hline $\begin{array}{l}\text { Política y } \\
\text { social }\end{array}$ & $\begin{array}{l}\text { Autodefensas: formadas en reacción } \\
\text { a la guerrilla; controlaban la zona } \\
\text { cuando la guerrilla salió del valle. }\end{array}$ & $\begin{array}{c}\text { Social, } \\
\text { coactivo, } \\
\text { político }\end{array}$ & Respalda & Negativo \\
\cline { 2 - 6 } & $\begin{array}{l}\text { Cocaleros: líderes de los productores } \\
\text { de coca. }\end{array}$ & $\begin{array}{c}\text { Social, } \\
\text { Económico, } \\
\text { político }\end{array}$ & Respalda & Negativo \\
\cline { 2 - 6 } & $\begin{array}{l}\text { Alcalde: autoridad política (muchas } \\
\text { veces se trataba de un líder cocalero). }\end{array}$ & $\begin{array}{c}\text { Social, } \\
\text { político }\end{array}$ & Respalda & Negativo \\
\cline { 2 - 6 } & $\begin{array}{l}\text { Juez de paz: autoridad legal } \\
\text { no-estatal }\end{array}$ & $\begin{array}{c}\text { Social, } \\
\text { político }\end{array}$ & Respalda & Negativo \\
\cline { 2 - 6 } & $\begin{array}{l}\text { Firmas locales: tienen una red de } \\
\text { tráfico, capacidades. }\end{array}$ & $\begin{array}{c}\text { Social, } \\
\text { coactivo }\end{array}$ & Respalda & Negativo \\
\hline Económica & $\begin{array}{l}\text { Carteles extranjeros: frecuentemente } \\
\text { denominados «colombianos». Eran } \\
\text { quienes traían mucho dinero al valle. } \\
\text { Usaban violencia para asegurar el } \\
\text { control de su negocio. Contrataban } \\
\text { sicarios. }\end{array}$ & $\begin{array}{c}\text { Económico, } \\
\text { coactivo }\end{array}$ & Respalda & Negativo \\
\hline
\end{tabular}

Fuente: Elaboración propia.

Según las entrevistas, ningún narcotraficante acaparó tanta importancia para ejecutar un poder directo e influir en el orden local. Su poder se basaba en el dinero y el uso selectivo de la violencia, pero no tenían una agenda política directa. Los «clanes de drogas», "firmas locales», que organizaron grandes operaciones de narcotráfico y producción de PBC no tenían una influencia política directa sino indirecta que estaba asegurada por su capital económico 
y coactivo. Según un análisis, había hasta seis clanes de narcotraficantes en el municipio de Monzón: "Los Rambos», «Scich», "Chilcano», "Lucho Flores», «Shiun», «Dionisio». En todo el distrito de Monzón, existían cuatro clanes más (Mella, 2012). Cada uno tenía una posición local y vías de transporte de drogas. Por ejemplo, Los Rambos tenían a la zona del Monzón como centro de operaciones y transportaban drogas principalmente a Bolivia y Chile.

Los agricultores comunes tenían poca influencia directa. Como los campesinos producían coca, la materia prima para la producción de la droga, fueron un elemento esencial en la cadena ilícita. Y con mucho, el grupo más grande en el valle. A pesar de que un campesino no tenía mucha influencia, sino que era más bien «un esclavo del sistema», ganaba mucho más cultivando coca que con cualquier otro cultivo, pero dependía de la demanda de la coca para la producción de droga; por eso era el eslabón más débil de la economía ilícita. La única manera de ganar poder fue con la ayuda de las asociaciones de coca, es decir, como parte de un sistema dirigido por líderes cocaleros. La mayoría de campesinos no acumuló riqueza durante los tiempos de auge de la coca.

Este sistema cerrado tuvo consecuencias extremas en la infraestructura. Como se mencionó anteriormente, no había servicio de teléfono, ni siempre contaban con agua corriente o electricidad y el sistema de aguas residuales no funcionaba. Socialmente, las consecuencias mencionadas comúnmente eran: borracheras (sesiones de beber alcohol pesado), frecuentes peleas dentro de bares o incluso asesinatos. Como el exdueño de un bar mencionó: «En aquellos días lo teníamos todo, lo ofrecíamos todo, chicas de afuera, whisky costoso, lo pediste y sin duda te podríamos ofrecer». Aún hoy se encuentran presentes recuerdos vivos de esa época, como este antiguo dueño de un bar — que era básicamente un burdel - que obtuvo grandes beneficios financieros durante este periodo; como él, hay muchos otros casos. Pero solo unos pocos invirtieron en empresas o casas estables. La moneda utilizada en Monzón fue sobre todo el dólar estadounidense, ya que fue el pago de elección por parte de los traficantes. El dinero «se deslizó por sus dedos», lo cual no era financieramente problemático, ya que había una afluencia constante. Este dinero no se utilizó para mejorar las condiciones de vida, en cambio la gente todavía recuerda el consumo excesivo de alcohol o la disponibilidad de ropa cara o motocicletas: «Bebía una caja de cerveza todos los días, todos los días podías ir de fiesta, gente tirada, borracha en la calle [...] ahora ya no bebo, no puedo». Desde la perspectiva histórica, hay dos líneas de argumentos, una que recuerda la regla más bien de una manera coercitiva, y otra que la recuerda como un factor vinculante de la sociedad que fue capaz de proveer un resultado económico adecuado. 
Muchos mencionaron que su situación personal mejoró en los últimos cinco años, pero un gran número de encuestados indica también que su situación empeoró.

Preguntando específicamente sobre percepciones de las reglas y el orden en los últimos quince años, es difícil obtener respuestas claras. Cuando se preguntó quién gobernó y cómo se organizó la regla, casi todos se refieren a la regla de la guerrilla, que se ha basado principalmente en la interferencia brutal, el incumplimiento, el castigo público y corporal. Pero, al mismo tiempo, todos se refirieron al tiempo anterior a la década de 1990. Cuando se les preguntó de forma más especifica cómo se encontraban las reglas y el orden después de que la guerrilla salió y no tenía más poder, la respuesta más frecuente fue «todo era tranquilo». De hecho, el gobierno local se construyó alrededor de la coca, proporcionando a aquellos que tuvieron una mayor influencia en la economía ilícita y la protección de la coca. Esto proporcionó especialmente a los líderes de coca más poder.

Con base en la información obtenida durante la investigación de campo, la posición dentro del campo se basó principalmente en la relación con la coca. Los actores poderosos dentro del campo de poder de la coca tenían una actitud positiva hacia la coca y negativa hacia el Estado. Los más poderosos eran los actores que también podían apoyar políticamente la economía de la coca. Después de que la guerrilla se fue, esta relación ha sido la más importante. Por otro lado, aquellos actores con menos poder también han sido menos solidarios con los cocaleros o incluso han estado en contra de la economía de la coca. La relación con la economía ilícita se convirtió en la precondición más importante para ganar poder. Es justo decir que la región cerrada de Monzón, con su economía de coca, representa su propio campo, incluyendo sus propias reglas y su estructura particular que es inseparable de la existencia de la coca. La posición de cada sujeto en el campo de la economía de la coca depende de la relación con la coca, de la acumulación de capital social, económico, coactivo y político. El gráfico 1 presenta la relación entre poder acumulado y el apoyo de la economía de la coca. Poder e influencia están basados en el capital acumulado. Por ello, el alcalde, los cocaleros o las autodefensas tienen más poder que los traficantes de menor escala o campesinos, porque su capital acumulado es mayor (véase gráfico 1). 


\section{Gráfico 1. Campo de poder de la coca}

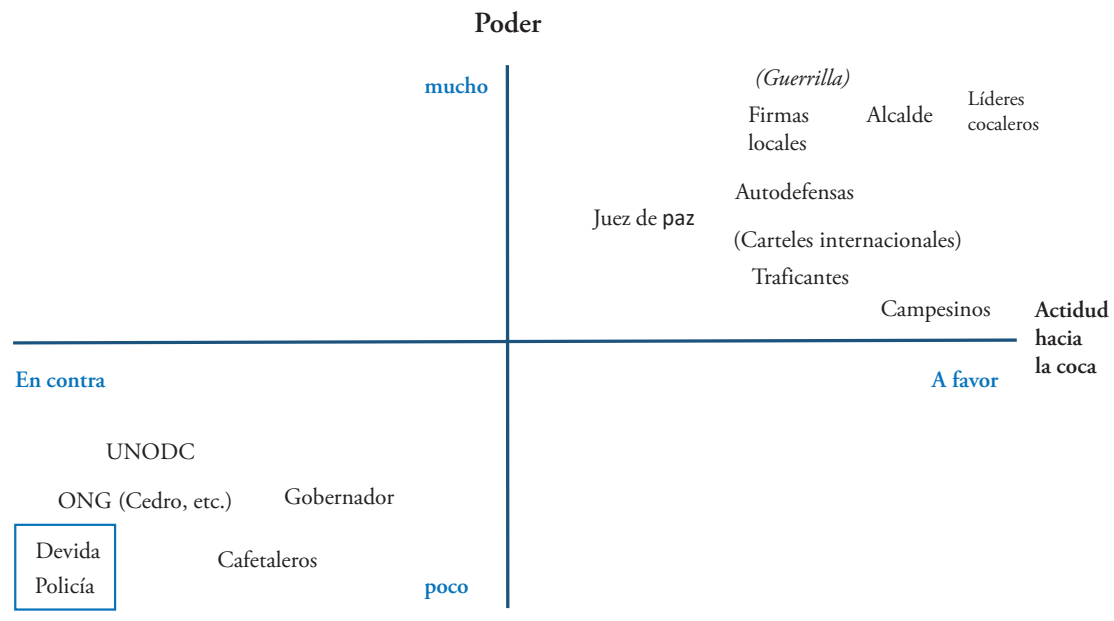

Fuente: Elaboración propia basado en entrevistas y cuestionarios realizados en el trabajo de campo.

En resumen, el orden y las reglas locales se basaban en la coca y en una amenaza desde el exterior. El nuevo orden y el apoyo a ese orden son relativamente nuevos y pueden verse, entre otros, a través de la confianza y la percepción de la población local. La coca y la economía ilícita fueron un factor dominante en Monzón. Incluían el desarrollo de normas y normas particulares como la participación en huelgas o el apoyo a los cultivos de coca. La coca fue el factor que unificó el área. Y todos los que entraban en Monzón o vivían en la zona sabían que así era. Este campo funcionó de manera autónoma del resto del país, pero el Estado trató de ganar influencia, en particular a partir de 2002.

\section{LA LLEgADA DEL ESTADO Y LA DISRUPCIÓN DEL CAMPO}

La presencia del Estado fue históricamente baja en el valle del Monzón, que es similar a la mayoría de las áreas en el Alto Huallaga. Duró hasta 2012, antes que el campo de poder de la coca fuera interrumpido por la erradicación forzada. En 2012 el valle representó alrededor de $11 \%$ a 15\% de toda la producción de coca en el Perú (UNODC, 2012). Antes de que el Estado entrara con más fuerza y pudiera asegurar su presencia en el valle, la situación era tensa y marcada por una larga historia de resistencia por parte del pueblo de Monzón en su lucha contra la erradicación forzada y el desarrollo alternativo. Posteriores a las primeras grandes campañas de erradicación, Monzón ya contaba con la imagen de ser rebelde y difícil durante las negociaciones sobre sus cultivos de coca. 
En 2003, por ejemplo, cuando ingresaron fuerzas estatales con 11 helicópteros y alrededor de 600 hombres para destruir las instalaciones locales de producción de cocaína, la gobernadora Alejandra Velarde tuvo que ser evacuada, para garantizar su seguridad, después de que los cocaleros la acusaran de cooperar con la Policía (Caretas, 2003). Las tensiones fueron altas, hasta que el líder cocalero local y alcalde de Monzón, Iburcio Morales, fue encarcelado en 2010 junto con otros 41 líderes cocaleros de la UHV durante la Operación Eclipse, esta operación fue un golpe principal al movimiento cocalero, y no solo para el valle del Monzón. En total, la Policía detuvo a 152 personas en Aucayacu, Tingo María y Monzón por denuncias de cooperar con Sendero Luminoso y por estar involucrados en el tráfico de drogas. En los enfrentamientos con la población local en 2012, dos personas murieron (IDL-Reporteros, 2012). Esta situación tensa se presentaba incluso antes, cuando trabajadores de Devida ingresaron al valle para promover proyectos de desarrollo alternativo Así, el caso de la zona de Monzón representa una penetración parcial de diferentes actores estatales que influyó primero en la posición de los actores más radicales y posteriormente en la transformación del campo.

Adicionalmente, el 12 de febrero de 2012 el líder de Sendero Luminoso en el Alto Huallaga, Florindo Eleuterio Flores Hala «Camarada Artemio», fue capturado. En una publicación reciente, Devida (2015, p. 11) vincula la captura de Artemio como un factor clave para pacificar la región y proporcionar orden. Con estas acciones se destruyó la defensa política y militar de la coca. Además, el movimiento cocalero nacional perdió influencia y capacidad de cabildeo al no tener representantes en el parlamento de 2011 a 2016 (Zevallos, 2016). En última instancia, no solo el mecanismo de defensa contra la erradicación, sino también la cohesión interna fue dañada. No mucho después de la captura de Artemio, el Estado entró en el valle del Monzón. Los argumentos a favor de la erradicación estaban bien definidos. Sin embargo, las autoridades locales, así como la organización de los cocaleros, estaban en contra de la erradicación, mientras que los agentes estatales y agencias de cooperación para el desarrollo estaban a favor. Estos actores que representaban a instituciones grandes sostuvieron que era necesario combatir el narcotráfico para desarrollar la región. Adicionalmente faltaba una plataforma local para la organización de la resistencia local, que hubiera podido fortalecer la cohesión interna, como lo hizo antes. Por otro lado, la cohesión de los agentes estatales fue un tema clave para el éxito de la campaña de erradicación (Zevallos, 2016). 
Gráfico 2. Producción de coca en Monzón (2011 y 2014)

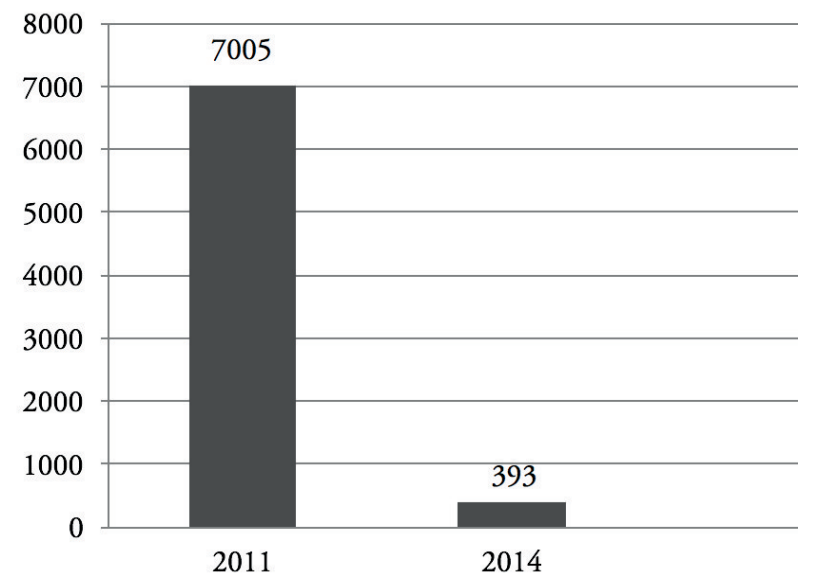

Fuente: Devida (2015).

De esta manera, en diciembre de 2012, Corah entró en la región con un triple plan de «erradicación, resocialización y desarrollo alternativo». La primera acción fue la campańa de erradicación, destruyendo cultivos de coca y laboratorios de cocaína. En los ańos siguientes, la acción estatal redujo la producción de coca de 7005 ha en 2011 a 393 ha en 2014 . Ello dio lugar a cambios económicos masivos, ya que la mayoría de los alrededor de 13 mil habitantes (INEI, 2007) dependían de la coca. La erradicación tuvo consecuencias dramáticas en el campo de gobierno. Así, podemos dividir la regla en un antes de la erradicación y después de la erradicación.

\section{EL CAMPO DE PODER POSCOCA}

Los cambios económicos ocasionados por la erradicación tuvieron mayores consecuencias para Monzón. La intervención estatal destruyó la base más importante para las posiciones influyentes en el campo de poder, la coca. Por tanto, construyó un campo de poder y afectó el orden local, que cambió drásticamente en los ańos siguientes.

Después de la erradicación, el Estado rápidamente instaló bases policiales. De esta manera, en el Monzón se encuentra la presencia de tres nuevas bases, una en Monzón Alto y otras dos en la parte baja del valle llamada Monzón Bajo. Es interesante observar que cada estación de Policía es resguardada todo el tiempo por un policía fuertemente armado. El poder estatal representado a través de la Policía es aceptado, pero las órdenes no son necesariamente compartidas, 
la aceptación depende también del jefe de policía local que cambia cada año. Un agente policial explica que están presionando incluso con el cumplimiento de normas menores, como usar un casco; una regla que antes nadie obedeció porque no había sanción. Incluso el juez de paz local dijo: «No estoy usando un casco cuando estoy conduciendo de un lado de la ciudad a la siguiente. ¿Para qué? Eso es una locura». Estas son posiciones comunes cuando se pregunta sobre nuevas normas y leyes después de la llegada del Estado. El agente policial señala que comienza con el paquete de reglas más pequeñas para mantener el orden en el distrito. El jefe también no niega las diferencias con su predecesor, pero destaca que, dada la larga ausencia de las autoridades estatales, las reglas deben ser implementadas "poco a poco». Sin embargo, la Policía es muy criticada, especialmente en lo que respecta a su lucha contra Sendero Luminoso. Muchos habitantes de Monzón todavía dicen que la Policía escapó y dejó abandonada a la gente cuando la guerrilla asumió el poder durante la década de 1980. Además, hay muchas quejas sobre mala conducta policial. Sin embargo, agregamos que las personas entrevistadas indican que hay menos violencia y venganzas personales hoy en día en comparación a la época donde primaba la regla de la coca. Aparte de las claras declaraciones sobre la difícil situación económica, hay pobladores que subrayan el trade-off: «Todavía hay narcos, pero pocos. Antes de que todos tuvieran plata, se vivía bien: comprar cosas, viajar [...] pero también las matanzas y los borracheros». Por lo tanto, observan una conexión clara entre la caída económica y menos violencia.

Los actores más poderosos dentro del nuevo campo son aquellos que implementan normas y reglas, y las supervisan. Si anteriormente todo dependió de la coca, ahora todo depende del Estado y de la relación con el Estado. Como consecuencia, los actores más importantes ya no apoyan la hoja de coca. Los actores no cambiaron por completo, pero su posición dentro del campo y su base de influencia sí lo hizo. Otros actores como la Policía o instituciones estatales en general lograron instalar su influencia, mientras que el número de los grupos que usaron o podían usar la violencia disminuyeron significativamente en relación a los primeros periodos. Antes de la erradicación del cultivo de coca que afianzaba a los narcotraficantes; firmas locales, sicarios, autodefensas usaban la violencia y tenían un capital coactivo. A esto también se agrega el uso de herramientas coercitivas por parte de la población para solucionar disputas. Es decir, no existía un monopolio de violencia por ningún actor. Ahora bien, la Policía es la única institución que puede utilizar eficazmente herramientas coercitivas, su principal base de poder es el capital coactivo. El alcalde sigue siendo la figura más influyente del distrito. Su forma de capital no ha cambiado, pero 
en lugar de su capacidad de defender la coca, ahora el alcalde es visto, a decir de los pobladores, como la figura más influyente debido a su capacidad para solicitar financiación pública. Las entidades gobernantes y poderosas, así como el personal de apoyo de la oficina de los alcaldes, son ahora pro desarrollo alternativo. Mientras que antes el capital económico, social y también cultural dependía de la coca, hoy es lo contrario. Ningún partidario de la coca tiene ahora una posición de liderazgo dentro de la comunidad. La posición de los políticos locales es más fuerte cuanto más demuestran la capacidad de atraer las inversiones estatales al valle.

Tabla 2. Actores poderosos en Monzón después de la erradicación

\begin{tabular}{|c|c|c|c|c|}
\hline Influencia & Actor & $\begin{array}{l}\text { Base de poder } \\
\quad \text { (capital) }\end{array}$ & $\begin{array}{l}\text { Actitud hacia } \\
\text { la coca }\end{array}$ & $\begin{array}{l}\text { Actitud hacia } \\
\text { el Estado }\end{array}$ \\
\hline \multirow{5}{*}{$\begin{array}{l}\text { Política y } \\
\text { social }\end{array}$} & Policía: monopolio de violencia & Coactivo & Negativo & Positivo \\
\hline & Alcalde: autoridad política & $\begin{array}{l}\text { Social, } \\
\text { económico, } \\
\text { político }\end{array}$ & Negativo & Positivo \\
\hline & $\begin{array}{l}\text { Gobernadores: representantes del } \\
\text { Estado }\end{array}$ & Social, político & Negativo & Positivo \\
\hline & $\begin{array}{l}\text { Autodefensas: todavía presentes. } \\
\text { Pero por causa de la policía, sin } \\
\text { tarea real }\end{array}$ & Social, político & Respalda & Negativo \\
\hline & Juez de paz: autoridad legal & Social, político & Respalda & Positivo \\
\hline \multirow[t]{2}{*}{ Económica } & $\begin{array}{l}\text { Devida: provisión de asistencia } \\
\text { económica y técnica }\end{array}$ & Económico & Negativo & Positivo \\
\hline & $\begin{array}{l}\text { Compañías de construcción: } \\
\text { provisión de oportunidades } \\
\text { laborales }\end{array}$ & Económico & Negativo & Positivo \\
\hline
\end{tabular}

La intervención estatal, a partir de la erradicación, mermó las posiciones más influyentes relacionadas directamente con la coca, dentro del campo de poder. Construyendo de esta manera un campo de poder que afectó el orden social, el cual cambiaría drásticamente en los años siguientes. En el nuevo campo de la 
poscoca, las condiciones para obtener el poder están basados en la relación que se mantendrá con el Estado. Ya que ahora los actores que apoyan la economía de la coca son aquellos con menos poder. Tener al menos una actitud crítica hacia la economía de la coca se convirtió en una condición previa para obtener poder.

Ahora bien, no hay una figura dominante, como Iburcio Morales durante el periodo de la coca, que gobierne a los líderes cocaleros. Pero el alcalde sigue siendo la institución más importante, pero ahora se legitima por su apoyo al Gobierno y no por el apoyo a la coca. Otro cambio importante incluye que algunos actores desaparecieron del campo, como firmas de drogas o contrabandistas.

\section{Gráfico 3. Campo de poder poscoca}

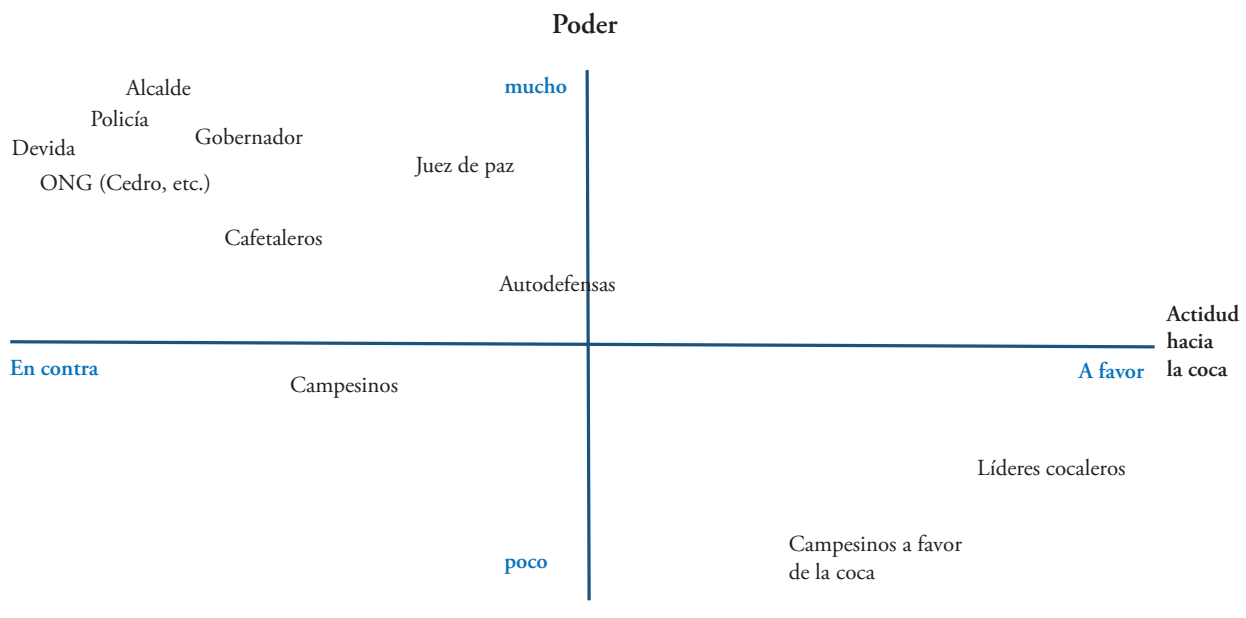

Fuente: Elaboración propia basado en entrevistas y cuestionarios realizados en el trabajo de campo.

El tema clave es la economía y las oportunidades financieras que faltan, ya que la coca se ha ido. Siendo esta una región que se formó y desarrolló alrededor de la economía ilícita, y cuya gente además socializó por medio de ella, esto influyó en cómo se acumuló el capital que funcionaba solo por medio de esta economía basada en la coca. Por tanto, los actores políticos y los actores poderosos miden su capacidad en función de gestionar y proporcionar apoyo económico, esta vez de parte del Estado. Esto se refleja por ejemplo en la condición del nuevo alcalde, que es el primero en no tener una posición a favor de la producción de la coca y el primero en no ser cocalero. Es, en contraste, un ingeniero que desempeña un papel importante atrayendo inversiones del Estado, así como logrando la instalación de la planta hidroeléctrica en el área. 
Además, una de las razones por las que entró a la alcaldía fue precisamente por su promesa de traer puestos de trabajo. Cuando se preguntó a la gente quién es el actor más poderoso, la mayoría respondió algo similar a «nadie, somos todos iguales», "todos somos pobres», o nombrando al alcalde: «el alcalde, porque es el único que puede buscar inversiones» (el argumento para esto también fue muy similar: "porque trae inversiones», "porque negocia con el Estado»). Por lo tanto, el poder ahora se relaciona principalmente con su conexión a la financiación del Gobierno, entonces el capital económico y el capital político está en relación con el Estado central.

Aunque una buena relación esta percibida como una condición necesaria para el desarrollo, la forma en que el Estado entró a la zona está lejos de ser aceptada por la mayoría de la población. Los funcionarios de Devida mencionan que comenzaron a comunicarse con la población antes de que se iniciara la erradicación, para sensibilizar en torno al desarrollo alternativo. Sin embargo, existen varias observaciones de la población similares a las siguientes: "No comunicaron nada. No hablaron con nosotros». En todas las entrevistas con la población local de Monzón, a pesar de que estuvieran a favor o en contra de la intervención estatal, esta era percibida como un grave error por parte del Estado. La gente se sintió ignorada y sus demandas no se tomaron en serio. En consecuencia, esto generó nuevos retos para los funcionarios del Estado, que fueron percibidos como invasores, lo cual fue una de las razones por la que la intervención estatal en Monzón fue disputada al principio, y cuestionada por las personas poderosas en el valle.

Monzón se encuentra ahora en un momento de transición. Los pobladores internalizaron la estructura local basada en la economía ilícita. En esta fase de transición hay dos opiniones principales. Para algunos, la coca sigue siendo el factor dominante para su pensamiento, esta vez causado por su ausencia. La intervención es entendida como causa de muchas consecuencias negativas, no solo económicamente sino también culturalmente y por temas de seguridad (robo, violencia, cambios de hábitos locales). Este grupo ha perdido económicamente y está claramente opuesto a la erradicación y el advenimiento del Estado. Pueden definirse como "perdedores» en la campaña de erradicación. Principalmente impulsados por las pérdidas económicas, sus principales quejas se refieren a la caída económica después de la pérdida de la coca, ya que los productos alternativos no producen ninguna alternativa real, la gente tuvo que salir de la región. Además, algunos pobladores argumentan que con la llegada de la justicia estatal, los mecanismos de la Policía no son suficientes para asustar a los ladrones y que las leyes protegen más a los ladrones que a la población. 
Por otro lado, el otro grupo, que se benefició de la campaña de erradicación, hace hincapié en cambios positivos, incluyendo los cambios en los hábitos locales, menos violencia y más posibilidades de desarrollo para todo el distrito. Este grupo se compone principalmente de cafetaleros con ambiciones de exportar sus productos y con elevadas y explícitas expectativas hacia el Estado, como la construcción de una fábrica café para agregar más valor a sus productos, o la mejora de calles para optimizar la capacidad de transporte.

Concluyendo la investigación de campo, la erradicación por parte del Estado ahora se percibe como un aspecto inevitable. Hay dos argumentos relativos sobre la erradicación por parte de la población. La mayoría de los entrevistados indicaron que no se oponen al Estado como tal y saludan a la mayoría de las agencias y servicios estatales. También dan la bienvenida a alternativas proporcionadas por el Estado. Pero esto está altamente vinculado con la economía que trae el Estado y la posibilidad de controlar la violencia. La situación económica aún se presenta frágil.

\section{Discusión: MonZón, UNA REgIón EN TRANSICIÓN}

La coca fue el factor decisivo para la sociedad de Monzón. El análisis histórico indica que durante la época del segundo boom de la coca, el Estado era una quimera y los actores estatales no tenían influencia en la región. La zona fue «colonizada» tardíamente y desde inicios de la década de 1940 la coca y posteriormente la economía ilícita de producción y tráfico de pasta básica dominó la zona. El boom de la cocaína dio lugar a oportunidades económicas que alimentó una ola migratoria. La migración a la zona llegó de forma abrupta y rápida y creó una comunidad relativamente joven que era muy diversa culturalmente. El único factor de conexión desde el inicio fue la coca, y con una influencia creciente de la economía de drogas. Mientras que el conflicto interno juega un papel importante en la memoria local, la coca y la economía ilícita son el tema dominante a lo largo de los años. Por lo tanto, históricamente la coca parece ser la más influyente para la constitución de la sociedad, incluyendo la producción de campos locales de gobierno. La larga historia de la producción de drogas ilícitas creó esferas sociales en las que la gente logró acumular poder por su papel en la economía ilícita, y por su voluntad y capacidad de utilizar la violencia. Estos poderosos actores incluían líderes cocaleros o importantes líderes de clanes de drogas. Los primeros tienen una posición política importante, como la alcaldía, que dio autoridad para proveer y dar forma al orden. Entre estos actores, el juez de paz o los gobernadores tuvieron roles importantes, aunque menores. 
El capital económico, social y político, y también el capital coactivo, están altamente relacionados con la economía ilegal. Básicamente, toda la población vivía de la economía ilícita directa o indirectamente. Aquellos que estaban en contra de la economía ilícita o que expresaron su deseo de cambio, se enfrentaron con la degradación social o sufrieron pérdidas financieras cuando sus cultivos fueron destruidos como forma de castigo. A menudo, esto se hacía de manera colectiva. Al vincular este análisis con el concepto de campos de poder, vemos que el capital de los actores más importantes se basa principalmente en la economía de la coca. El resultado económico depende sobre todo de la producción de coca y PBC, así como de la producción y el contrabando de drogas. El capital social — que depende principalmente del papel que desempeńan en las estructuras sociales los procesos de toma de decisiones, principalmente a través de canales formales y de actores con un alto capital coactivo- estaba respaldado por la coca8 .

Como la coca fue el factor constitutivo, el campo de poder en la región de Monzón se ha constituido principalmente a causa de la economía ilícita de la coca. La relación de los diferentes agentes y el reconocimiento de su poder se pueden rastrear a través de su relación con la economía ilícita. Toda la vida social dependía de la economía ilícita y la movilidad social ascendente estaba conectada a ella. Eso no solo daba más influencia para aquellos con la conexión más cercana a la producción de coca, sino que también era un sistema cerrado, y nadie de afuera podía entrar sin permiso de los líderes. Por lo tanto, el campo se definió internamente a través de la relación de los diferentes agentes con la economía ilícita. Adicionalmente, se definió en contra de los campos externos de la norma, que se consideraban una amenaza para la economía interna y el orden social. De esta manera, la amenaza de la erradicación definió la forma en que se percibía a los extraños y, en última instancia, a los agentes estatales. Había un círculo interior que necesitaba protección contra el exterior, es decir del Estado que quería destruir esta economía ilícita. Por eso, la ilegalidad es una fuente de poder para aquellos que protegen los bienes ilegales. Esto produce un modelo interno-externo que una vez más apoya la acumulación de poder, y por tanto, el propio Estado aumentó la alienación de una región ya periférica.

Entonces el aspecto más importante para la unión de la sociedad fue la coca, como fuente de poder a través de diferentes capitales, como conexión entre

\footnotetext{
8 No se mencionó en el análisis un capital cultural. Dentro de una sociedad de la coca, cuya cultura se mezcla con altas tasas de migración, las bases culturales son relativamente débiles. Lo que se aprende como persona joven en este campo es cómo conducirse dentro de la economía ilícita. No es importante aprender o ir a la escuela, sino trabajar la coca, producir PBC o traficar droga. De nuevo, el factor vinculante es la economía ilícita de la coca.
} 
diferentes agentes, y como distinción al Estado como otro campo de poder. Por tanto, se puede deducir que la economía de la coca produjo un campo de poder en sí mismo en el que ciertos agentes podían ganar poder y confianza, pero solo a través de su relación con la economía de la coca. La acumulación de capital (social, económico o cultural) solo era posible a través de la economía ilícita. Los agentes se influencian mutuamente, pero su poder estaba basado en y conectado a través de la exclusiva economía de la coca y apoyado por un «enemigo» externo: los agentes estatales. Sin embargo, no todos los actores dentro de ese campo son considerados como actores poderosos legítimos por todos. Esto se puede observar por el uso de la violencia contra las personas que se oponen a los actores gobernantes. Pero la conexión con la economía de la coca y el apoyo de la mayoría de la población permitió a esos actores mantener su posición.

Tras la intervención estatal, algunos actores desaparecieron completamente, como los cocaleros debido al encarcelamiento, la muerte o la migración y porque los campesinos cambiaron sus cultivos de coca por cultivos alternativos; y los narcotraficantes porque ya no había más producción de droga. Otros actores son nuevos: Devida y la Policía — con presencia permanente- y con ellos llegaron fuentes externas de capital. Ahora se amplía el campo de gobierno, por lo que por primera vez no es necesario tener relaciones estrechas con la industria de la coca. Por primera vez el alcalde no es un cocalero. En cambio, su legitimidad se basa sobre todo en su capacidad para asegurar el desarrollo económico y de infraestructura. Ambos ahora dependen principalmente del Estado. Más que nada a través de la relación con Devida - o en las propias iniciativas, como cafetaleros-, que produce figuras influyentes.

\section{Conclusión}

La intervención estatal y la destrucción de la economía ilícita redujeron la relación entre los diferentes actores, ya que los cultivos de coca y la economía ilícita eran el principal vínculo de los actores dentro de la sociedad. La intervención redefinió el concepto de capital y por ello el poder de los diferentes actores dentro del campo. Dentro del nuevo campo de la regla, los actores más poderosos actúan de acuerdo con las normas estatales precisamente por estar en el poder a causa del Estado. Así que la presencia del Estado ahora es lo más importante para la definición del campo y la distribución del poder. La conexión con el Estado y especialmente la financiación estatal se convierten también en una forma de capital. Los que están cerca del Estado, económicamente o proporcionando seguridad, tienen más poder dentro del campo. 
El subdesarrollo durante el auge de la coca fue percibido como un sacrificio necesario para ser independiente, ahora la expectativa es que actores poderosos apoyen el desarrollo de la región. Una posición prominente la tiene el alcalde, que se espera que aplique para las inversiones por el Estado y el desarrollo del distrito. La economía ilícita era la forma más importante de obtener capital político, social o económico. Ahora es el Estado quien asume esa posición, por ello la relación con los actores estatales es importante, así como el acceso a los canales de las inversiones estatales, siendo, de esta manera, los aspectos esenciales para acumular capital y por lo tanto poder. Ahora ya no es fundamental la defensa de la coca y la economía ilícita, sino la provisión de alternativas viables y la construcción de infraestructura.

Este último punto nos deja entender la efectividad de la intervención del Estado. La intervención que se observó destruyó la base del campo de poder que fue la coca y la economía ilícita. Pero esto, como tal, no significa que el nuevo campo se encuentra estable, ni que la intervención estatal sea efectiva. Aunque se ve que el acceso a actores del Estado y distintos canales de financiamiento son clave para generar capital, esto aún no significa que haya un control sólido del Estado. Al contrario, los actores no-estatales podían asumir poder porque su rol era esencial para la cohesión social, la integridad territorial y sobre todo para el ingreso económico. Este campo de poder funcionó porque fue provechoso para la mayoría de la población. Que los nuevos actores poderosos en el campo de poder puedan garantizar lo mismo, todavía no está claro. Esto tiene que ver con las posibilidades económicas, los servicios básicos y además por la capacidad de control social. Lo último parece clave para garantizar un campo de poder. Las reacciones de la población local sugieren que no existe una gran confianza en el nuevo orden social y que puede cambiar otra vez. Intervenciones en regiones históricamente al margen de la influencia del Estado se pueden implementar como un nuevo campo de poder, pero se necesita tiempo para producir estabilidad a base de una economía estable y segura. El éxito en esto es clave para establecer el nuevo campo de poder, que esta vez está basado en la relación con el Estado. Por ello, el caso de Monzón puede ser ilustrativo para otras zonas cocaleras o regiones al margen del Estado que son dominadas por economías ilícitas.

Para concluir, la economía ilícita fue la base del gobierno local y el núcleo del campo de poder. Es por eso que al destruir los cultivos de coca, el Estado destruyó la base misma del campo de poder. En segundo lugar, la intervención no solo destruyó el campo existente, sino que creó uno nuevo, que al mismo tiempo crea diferentes oportunidades para obtener capital dentro de este nuevo 
campo. Por lo tanto, si estamos hablando sobre economías ilícitas en regiones al margen del Estado, toca analizar también el campo de poder que produce. Se puede leer esto como un éxito desde el punto de vista de la formación del Estado, pero la sostenibilidad de la destrucción de la base de capitales es dudoso. Se necesita una alternativa válida para generar un nuevo campo de poder estable y sostenible. Si no se producen estas alternativas, es probable que el campo de poder cambie otra vez.

\section{REFERENCIAS}

Abello-Colak, A. y Guarneros-Meza, V. (2014). The Role of Criminal Actors in Local Governance. Urban Studies, 15(15), 3268-3289. https://doi.org/10.1177/0042098013519831

Andreas, P. (2013). Smuggler Nation: How Illicit Trade Made America. Nueva York, NY: Oxford University Press.

Arias, D. E. (2010). Understanding Criminal Networks, Political Order, and Politics in Latin America and the Caribbean. En Clunan, A. y Harold, T. (eds.), Ungoverned Spaces: Alternatives to State Authority in an Era of Softened Sovereignty. Stanford, CA: Stanford University Press.

Arias, D. E. (2006). The Dynamics of Criminal Governance: Networks and Social Order in Rio De Janeiro. Journal of Latin American Studies, 38(2), 293.325. https://doi.org/10.1017/ S0022216X06000721

Bourdieu, P. (1986). The Forms of Capital. En J. G. Richardson (ed.), Handbook of Theory and Research for Sociology of Education (pp. 241-58). Westport, CT: Greenwood.

Bourdieu, P. (1990) The Logic of Practice. Stanford, CA: Stanford University Press.

Bourdieu, P. (1991). Political Representation: Elements for a Theory of the Political Field. En P. Bourdieu, Language and Symbolic Power (pp. 171-202). Harvard, MA: Cambridge University Press. https://doi.org/10.2307/202032

Bourdieu, P. (1993) The Field of Cultural Production. Columbia University Press.

Bourdieu, P. (1994). Rethinking the State: Genesis and Structure of the Bureaucratic Field. Sociological Theory, 12(1), 1-18.

Bourdieu, P. (2010) [1984]. Distinction: A Social Critique of the Judgement of Taste. Londres: Routledge.

Devida (2013). Diagnóstico Socioeconómico y Ambiental de la Cuenca Baja del Valle de Monzón. Recuperado de: http://www.simdev.gob.pe/seccion/documentos

Devida (2015). Recuperando el Monzón. Serie Seguridad y Desarrollo Alternativo. Lima: Observatorio Peruano de Drogas.

Durand Guevara, A. (2005). El movimiento cocalero y su (in)existencia en el Perú. Itinerario de desencuentros en el río Apurímac. Bulletin de l'Institut Francais d'études, 34(1),103-126.

Durand Ochoa, U. (2014). The Political Empowerment of the Cocaleros of Bolivia and Peru. Basingstoke, Inglaterra: Palgrave Macmillan. https://doi.org/10.1057/9781137453556

Haugaard, M. (1997). The Constitution of Power: a Theoretical Analysis of Power, Knowledge and Structure. Manchester: Manchester University Press.

Kurtz, M. (2013). Latin American State Building in Comparative Perspective: Social Foundations of Institutional Order. Nueva York, NY: Cambridge University Press. https://doi.org/10.1017/ cbo9781139019668 
López, N. y Tuesta, D. (2015). Economías ilícitas y orden social: la frontera de Perú, Brasil y Colombia. Revista CIDOB d'Afers Internacionals, (111), 79-104.

Lukes, S. (1978). Power and Authority. En T. B. Bottomore y Robert, A N. (eds.), A History of Sociological Analysis (pp. 633-676). New York: Basic Books.

Meagher, K. (2014). Smuggling Ideologies: From Criminalization to Hybrid Governance in African Clandestine Economies. African Affairs, 113(453), 497-517. https://doi.org/10.1093/afraf/ adu057

Meehan, P. M. (2015). Fortifying or Fragmenting the State? The Political Economy of the Opium/ Heroin Trade in Shan State, Myanmar, 1988-2013. Critical Asian Studies, 47(2), 253-282. doi. org/10.1080/14672715.2015.1041280

Müller, H-P. (2014). Pierre Bourdieu. Eine systematische Einführung. Berlin: Suhrkamp Taschenbuch.

O’Donnell, G. (2004). The Quality of Democracy: Why the Rule of Law Matters. The Journal of Democracy, 15(4), 32-46. https://doi.org/10.1353/jod.2004.0076

O’Donnell, G. (1993). On State, Democratization and some Conceptual Problems (A Latin American View with Glances at Some Post-Communist Countries. World Development, 21(8), 1355-1369. https://doi.org/10.1016/0305-750X(93)90048-E

Soifer, H. D. (2015). State Building in Latin America. Nueva York, NY: Cambridge University Press. doi.org/10.1017/CBO9781316257289

Swartz, D. L. (2013). Symbolic Power Politics and Intellectuals. The Political Sociology of Pierre Bourdieu. Chicago, IL: University of Chicago Press. https://doi.org/10.7208/ chicago/9780226925028.001.0001

Van Dun, M. (2009). Cocaleros. Violence, Drugs and Social Mobilization in the Post-Conflict Upper Huallaga Valley, Peru. Tesis de Doctorado. Utrecht University Repository. https://dspace.library. uu.nl/handle/1874/33733

Vizcarra, S. y Zevallos, N. (2015). Hacia un modelo de focalización y priorización de intervenciones estatales antidrogas. En J. Mujica y N. Zevallos (eds.), Herramientas y métodos de análisis sobre el tráfico de cocaína (pp. 38-53). Lima: Comisión Nacional para el Desarrollo y Vida sin Drogas, Escuela de Gobierno y Políticas Públicas de la Pontificia Universidad Católica del Perú, Laboratorio de Criminología PUCP.

Weber, Max (2010). Wirtschaft und Gesellschaft. Frankfurt a. M.: Zweitausendeins.

Zevallos, N. (2016). Capacidades estatales y resistencias a la erradicación de cultivos: una mirada al Monzón. RITA - Revue Interdisciplinaire de Travaux sur les Amériques, (9). Recuperado a partir de http://www.revue-rita.com/notesderecherche9/capacidades-estatales-y-resistencias-ala-erradicacion-de-cultivos-una-mirada-al-monzon.html

\section{Fuentes estadísticas e informes}

INEI (2014). Tecnologías de la Información y Telecomunicación. Online: https://www.inei.gob.pe/ estadisticas/indice-tematico/tecnologias-de-la-informacion-y-telecomunicaciones

INEI (2007). Censo Online. http://censos.inei.gob.pe/Censos.

UNODC (2012). Perú: Informe de Monitoreo de Cultivos de Coca 2011. Lima.

UNODC (2015). Perú: Informe de Monitoreo de Cultivos de Coca 2014. Lima.

\section{Fuentes periodísticas}

Caretas (13 de noviembre de 2003). La conquista del Monzón. Caretas. http://www.caretas.com. pe/2003/1798/articulos/monzon.html. Fecha de la última consulta: 12 de julio de 2017.

Correo (15 de octubre de 2012). Exalcalde de Monzón murió en hospital Hipólito Unanue. Diario Correo. http://diariocorreo.pe/ciudad/exalcalde-de-monzon-murio-en-hospitalhipolit-224821/. Fecha de la última consulta: 12 de julio de 2017. 
IDL-Reporteros (22 de octubre de 2012). Los muertos de Monzon. IDL-Reporteros. https://idlreporteros.pe/los-muertos-del-monzon/. Fecha de la última consulta: 12 de julio de 2017.

Mella, Romina (3 de agosto de 2012). Los traficantes del Huallaga. IDL-Reporteros. https://idlreporteros.pe/los-traficantes-del-huallaga/. Fecha de la última consulta: 12 de julio de 2017.

Redacción LR (18 de febrero de 2004). Nadie puede erradicar sembríos de hoja de coca en el valle del Monzón. Diario La República. http://prod.larepublica.pe/politica/365765-nadie-puedeerradicar-sembrios-de-hoja-de-coca-en-el-valle-del-monzon. Fecha de la última consulta: 12 de julio de 2017. 